\title{
The incorporation of drug molecules with poor water solubility into polypyrrole as dopants: Indomethacin and sulindac
}

\author{
Eimear M. Ryan, Carmel B. Breslin* \\ Department of Chemistry, Maynooth University, Maynooth, Co. Kildare, Ireland
}

\section{A R T I C L E I N F O}

\section{Article history:}

Received 19 October 2018

Received in revised form

11 November 2018

Accepted 16 November 2018

Available online 17 November 2018

\section{Keywords:}

Polypyrrole

Poorly soluble drugs

Sulindac

Indomethacin

Ethanol

\begin{abstract}
A B S T R A C T
There is considerable interest in the development of polypyrrole-based drug delivery systems. However, it is not possible to incorporate drugs with limited water solubility into polypyrrole from the usual aqueous-based electropolymerisation solutions. In this study, two drugs with poor solubility in water, sulindac and indomethacin, were incorporated within polypyrrole films as dopants from an ethanol -containing electropolymerisation solution to give PPyIndo and PPySul. An organic perchlorate salt was added to the electropolymerisation solution and the resulting perchlorate dopant anions were released initially on reducing the PPyIndo and PPySul at $-0.70 \mathrm{~V}$ vs SCE. The drug molecules were then re -doped in the absence of the perchlorate salt. On reduction of the polymer films the sulindac and indomethacin were released into an aqueous saline solution, giving approximately $0.12 \mathrm{mg} \mathrm{cm}^{-2}$ of sulindac and $0.29 \mathrm{mg} \mathrm{cm}^{-2}$ of indomethacin over a 60 min release period. The greater amounts of indomethacin released from PPyIndo were explained in terms of higher doping levels. The doping levels of indomethacin and sulindac were estimated at 0.28 and 0.10 , respectively, using electrochemical quartz crystal microbalance measurements.
\end{abstract}

() 2018 Elsevier Ltd. All rights reserved.

\section{Introduction}

Conducting polymers, and in particular polypyrrole, have received much attention in recent years and this is largely connected to their wide range of potential applications that extend from sensors and biosensors [1] to drug delivery applications [2-11]. Polypyrrole can be easily converted between its oxidised and reduced states and during this process anions or cations are incorporated or released to maintain charge balance. This uptake and release has been linked with drug delivery and consequently there is much interest in the development of polypyrrole-based drug delivery systems [2-11]. For anionic drugs, the drug acts as a dopant during the electropolymerisation of the pyrrole monomer and it is subsequently released on reduction of the polymer. To facilitate the release of cationic species, large immobile dopants are incorporated within the polymer and then the cations are released on oxidation of the polypyrrole films. Using this approach, various drug molecules, including glutamate [2], dopamine [4], chlorpromazine [5], progesterone [6], neurotrophins [9], penicillin and

\footnotetext{
* Corresponding author.

E-mail address: Carmel.Breslin@mu.ie (C.B. Breslin).
}

streptomycin [10] and dexamethasone [3,7,11] have been incorporated and released from polypyrrole using an electrical stimulation. In addition to controlling the charge on the polymer backbone, electrical stimulation gives rise to volume changes in the bulk polymer and changes in the hydrophilic/hydrophobic character of the polymer [12] and these have an additional effect on the delivery of the drug.

It has been reported in a number of studies that polypyrrole has good biocompatibility properties. Almira et al. [13] have shown that polypyrrole substrates are suitable for the attachment and proliferation of mouse stem cells, making it a good candidate for biomedical applications where adhesion and the proliferation of stem cells is required. George et al. [14] surgically implanted polypyrrole in the cerebral cortex of a rat and concluded that the polypyrrole implants offered good biocompatibility properties. These studies indicate that polypyrrole has sufficiently good biocompatibility properties and when doped with drug molecules, as opposed to other anions that may have some toxicity, polypyrrole-loaded drug implants have the potential to be employed without any toxicity concerns.

The limitations in the application of polypyrrole as a drug-delivery system include the drug loading capacity and the variety of drug molecules that can be used. An increase in polymer 
thickness generally correlates with an increase in the total amount of drug that can be released [12]. However, the concentration released does not increase linearly with film thickness, with thinner films releasing a greater percentage of the incorporated drug. More recent attempts to increase the loading and concentration of the drug, include increasing the surface area of the polymer [15], combining micelles with polypyrrole [16] or nanowire networks that can be used as a reservoir to store drugs [17].

These investigations have all been carried out with water soluble or reasonably soluble drugs. However, there are a number of drug molecules that have limited or poor solubility in water. The aim of this study was to determine if drug molecules with poor water solubility could be incorporated into polypyrrole as dopants and subsequently released in an aqueous environment, to give a polypyrrole drug delivery system for the release of poorly soluble drugs. Two medium sized drugs, with limited water solubility, were selected. In order to provide a suitable concentration of the drug molecules in solution an ethanol-containing medium was chosen as the electropolymerisation solution. Although there are a number of reports describing the electropolymerisation of pyrrole in acetonitrile or acetonitrile and water mixtures [18,19], there are few mentions of ethanol [20]. Therefore, the formation of the polymers in the ethanol-containing solution was studied initially, then results are presented and discussed on the exchange properties and on the release of the drug molecules in an aqueous saline solution.

\section{Experimental method}

Cyclic voltammetry and current-time plots were carried out using a Solartron (Model SI 1287) potentiostat. A standard three electrode cell was used for all experiments. A high surface area platinum wire served as the counter electrode and a saturated calomel (SCE) electrode was used as the reference in all experiments carried out at room temperature, while a silver wire reference electrode was used at higher temperatures, designated as $\mathrm{Ag} \mid \mathrm{Ag}^{+}$. The potential of this wire was measured against the SCE reference before and after each experiment, and no significant drift was observed. A platinum disc electrode (99.99\% purity) with a surface area of $0.125 \mathrm{~cm}^{2}$ was employed as the working electrode (the surface area of the Pt electrode (and not the polymer) is used to express the drug release data in $\mu \mathrm{mol} \mathrm{cm}^{-2}$ ). This electrode was fabricated by embedding a platinum rod in a Teflon holder, which was filled with epoxy resin and a copper wire was threaded into the base of the metal sample for electrical contact. The exposed surface was polished to a mirror finish using successively smaller sizes of diamond paste to a final size of $1 \mu \mathrm{m}$ on a microcloth (Buehler). The surface of the platinum electrode was then rinsed with distilled water, cleaned in an ultrasonic bath to remove any polishing residues and finally dried in a stream of air.

The chemicals used throughout this study were purchased from Sigma-Aldrich (Analar grade reagents). Pyrrole was vacuum-distilled and stored in the dark at $-20^{\circ} \mathrm{C}$, while ethanol was distilled prior to use. However, the ethanol contains trace amounts of water, as absolutely water-free ethanol is difficult to maintain. All other chemicals were used as supplied. As the drug molecules, indomethacin sodium salt (NaIndo) and sulindac sodium salt (NaSul), have poor solubility in water, the electropolymerisation of pyrrole was carried out in ethanol at 36 or $40^{\circ} \mathrm{C}$. A $0.20 \mathrm{M}$ pyrrole solution was used and the conductivity of the solution was increased by adding tetrabutylammonium perchlorate (TBAP). The NaIndo was dissolved in ethanol to give a $0.20 \mathrm{M}$ solution of NaIndo and a $0.16 \mathrm{M}$ solution of TBAP at $36^{\circ} \mathrm{C}$. The pyrrole was added before the electropolymerisation reaction was carried out. The NaSul was somewhat less soluble in ethanol, and therefore a $0.12 \mathrm{M}$ solution of NaSul with $0.08 \mathrm{M}$ TBAP was employed and the electropolymerisation reaction was carried out at $40{ }^{\circ} \mathrm{C}$. The conductivity of the final solutions was 1.78 and $1.63 \mathrm{mS}$ for the NaIndo and NaSul, respectively. The concentration of TBAP was chosen to give similar conductivities and to give a drug/TBAP ratio $>1.2$. The somewhat higher temperature of $40^{\circ} \mathrm{C}$ was employed with sulindac as the salt is slightly less soluble in ethanol.

Electrochemical quartz crystal microbalance (EQCM) experiments were carried out on a Chi400 EQCM instrument. The polymers were deposited onto polished gold quartz crystal electrodes (Cambria Scientific) with an exposed surface area of $0.203 \mathrm{~cm}^{2}$. A Pt wire and a custom-made $\mathrm{Ag} \mid \mathrm{AgCl}$ reference electrode were used to complete the cell. The cell was placed in a chamber with a heater that was employed to control and maintain the temperature at $36^{\circ} \mathrm{C}$ or at $40^{\circ} \mathrm{C}$. The surface morphology of the polymer samples was obtained using a Hitachi SEM. The samples were sputter coated with gold using an Emitech K550x gold sputter coater prior to analysis.

The release of the two drug molecules from the polypyrrole matrix was monitored using UV-visible spectroscopy. The polymers were formed at $0.90 \mathrm{~V} \mathrm{vs} \mathrm{Ag} \mid \mathrm{Ag}^{+}$to a constant charge density of $2.8 \mathrm{C} \mathrm{cm}^{-2}$, they were removed from the electropolymerisation solution and placed in ethanol at $36^{\circ} \mathrm{C}$. The solution was agitated for $20 \mathrm{~min}$ to facilitate the diffusion of any drugs that remained within the polymer matrix as salts. Prior to the drug release experiments, the polymer was thoroughly washed in acetone, then immersed in distilled water and polarised at $0.50 \mathrm{~V}$ vS SCE for a 15 min period. A Cary 50 UV-Visible spectrometer was employed to give calibration curves, which were then used to compute the concentration of the drug released from the polypyrrole films. The release studies were carried out in an aqueous solution of $0.10 \mathrm{M}$ $\mathrm{NaCl}$. All release studies were repeated three times and the standard error was calculated using Eq. (1).

Standard Error $=\frac{\text { Standard Deviation } / \sqrt{\mathrm{n}}}{\text { Mean Current }} \times \frac{100}{1}$

\section{Results and discussion}

The structures of indomethacin and sulindac, presented as the sodium salts, are shown in Fig. 1. These salts were chosen to give anionic drug molecules that are capable of acting as dopants during the formation of the polypyrrole matrix. Although there are very few reports detailing the formation of polypyrrole from ethanol-containing solutions [20], this medium enabled the electropolymerisation of pyrrole in the presence of NaIndo and NaSul, which have limited solubility in water.

\subsection{Formation of PPyIndo and PPySul}

The influence of the applied potential on the rate of electropolymerisation in ethanol was initially studied to determine suitable potentials that can be employed to deposit polymers with good conductivity. In Fig. 2, current-time plots and the corresponding charge-time plots are shown for the electropolymerisation of pyrrole in the presence of NaIndo at $0.70 \mathrm{~V}$, $0.80 \mathrm{~V}$ and $0.90 \mathrm{~V}$ vs $\mathrm{Ag} \mid \mathrm{Ag}^{+}$at $36^{\circ} \mathrm{C}$ to generate PPyIndo. Similar data, shown as charge-time plots, are presented in Fig. 3 for the NaSul system. As evident from Fig. 2, the rate of electropolymerisation increases on increasing the applied potential, which is consistent with the higher rate of electropolymerisation at higher potentials observed with aqueous systems. While some of the charge is related to the deposited conducting polymer and this charge will increase as more conducting polymer is deposited, a 
(a)

(b)<smiles>COc1ccc2c(c1)c(CC(=O)O)c(C)n2C(=O)c1ccc(Cl)cc1</smiles><smiles>CC1=C(CC(=O)O)c2cc(I)ccc2/C1=C\c1ccc(S(C)=O)cc1</smiles>

Fig. 1. (a) Indomethacin sodium salt (NaIndo) and (b) sulindac sodium salt (NaSul).

significant portion of the charge is also connected with the oxidation of the pyrrole monomer. Therefore, the gradient of the charge-time plot can be used to provide an estimate of the rate of polymer deposition, while any deviation from the linear trend would indicate a loss in the conductivity of the deposited polymer. The average rate of electropolymerisation at $0.90 \mathrm{~V}$ vs $\mathrm{Ag} \mid \mathrm{AgCl}$ was calculated as $2.9 \times 10^{-4} \mathrm{C} \mathrm{s}^{-1}\left(2.32 \times 10^{-3} \mathrm{C} \mathrm{cm}^{-2} \mathrm{~s}^{-1}\right)$ for PPyIndo and $2.5 \times 10^{-4} \mathrm{Cs}^{-1}\left(2.0 \times 10^{-3} \mathrm{C} \mathrm{cm}^{-2} \mathrm{~s}^{-1}\right)$ for PPySul. The formation of PPyIndo is somewhat faster and this is probably connected to the higher concentration of NaIndo used. There is little difference between the size of the two drug molecules, the molecular weights of indomethacin and sulindac are $357 \mathrm{~g} \mathrm{~mol}^{-1}$ and $356 \mathrm{~g} \mathrm{~mol}^{-1}$, respectively, while the conductivity of the electropolymerisation solutions is similar. The charge-time plots are linear, giving a constant rate of electropolymerisation, with no evidence of any loss in the conductivity of the deposited polymer. This may be connected with the presence of ethanol. Indeed, Ovando-Medina et al. [20], observed an increase in the electrical conductivity of polypyrrole nanoparticles with an increase in the alcohol content. This was attributed to a longer conjugation length. Very good reproducibility was achieved with this system. The time required to give a total charge of $0.35 \mathrm{C}\left(2.8 \mathrm{C} \mathrm{cm}^{-2}\right)$ at $0.90 \mathrm{~V}$ vs $\mathrm{Ag} \mid \mathrm{Ag}^{+}$was measured as $1200 \pm 30 \mathrm{~s}$ for PPyIndo and $1400 \pm 30 \mathrm{~s}$ for PPySul. These data show that it is possible to form conducting PPyIndo and PPySul at potentials between $0.70 \mathrm{~V}$ and $0.90 \mathrm{~V}$ vs $\mathrm{Ag} \mid \mathrm{Ag}^{+}$in ethanol, and by using a constant fixed charge

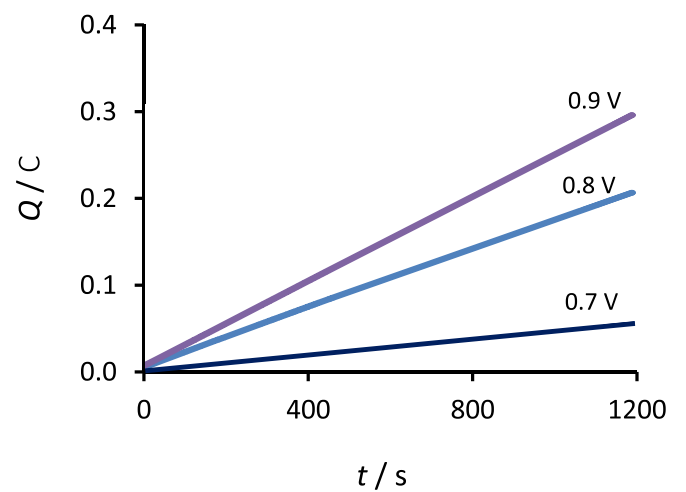

Fig. 3. Charge-time plots for the formation of PPySul at $0.70 \mathrm{~V}, 0.80 \mathrm{~V}$ and $0.90 \mathrm{~V}$ vs $\mathrm{Ag} \mid \mathrm{Ag}^{+}$in the presence of $0.12 \mathrm{M} \mathrm{NaSul}, 0.08 \mathrm{M}$ TBAP and $0.20 \mathrm{M}$ pyrrole in ethanol.

$\left(2.8 \mathrm{C} \mathrm{cm}^{-2}\right)$, similar amounts of polymer can be deposited in each experiment.

Apart from water, the electropolymerisation of pyrrole has been studied extensively in acetonitrile. In particular, the marked effect of water on the rate of electropolymerisation of pyrrole from acetonitrile has long been known $[18,19]$. This effect has been explained in terms of the higher dielectric constant of water (80 compared to 37 for acetonitrile) which reduces the Coulombic repulsion between the radical cations, facilitating radical-radical coupling [19]. An alternative explanation involves the fact that water is a fairly strong base in acetonitrile and prevents the acid-catalyzed formation of a pyrrole trimer, $2,2^{\prime}-\left(2,5^{\prime}-\right.$ pyrrolidinediyl $)$ dipyrrole, by capturing the released protons [18]. Passivation of the electrode occurs if this pyrrole trimer is subsequently electropolymerised, resulting in partially conjugated polypyrrole. The dielectric constant of ethanol is considerably lower than water $\left(€=25.3\right.$ at $20^{\circ} \mathrm{C}$ and 22.08 at $40^{\circ} \mathrm{C}$ ) making it a poor medium to reduce the Coulombic repulsion between the radical cations. However, ethanol with a pKa of -1.93 compared to the pKa of pyrrole, which is -3.8 [18], is more basic that pyrrole, facilitating the capture of the released protons and preventing the formation of the trimer, but not deprotonating other intermediate species that are essential during the electropolymerisation process. It appears that ethanol has a suitable combination of a $\mathrm{pKa}$ value and dielectric constant, making it an appropriate solvent for the electropolymerisation of pyrrole.

Micrographs are shown for the PPyIndo and PPysul in Fig. 4. The typical cauliflower or globular structures are evident for both systems, consistent with a number of previous reports [21]. The (a)

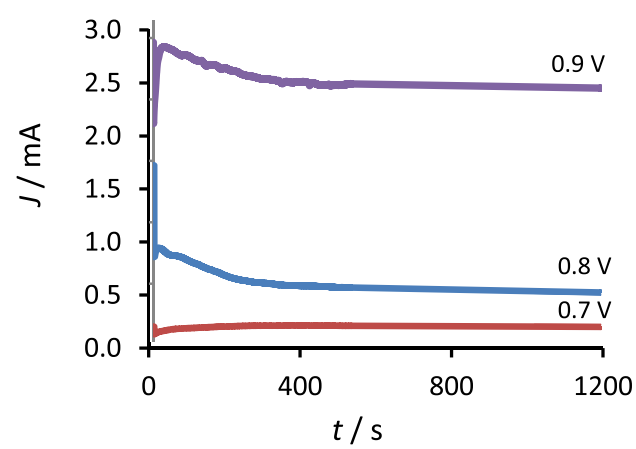

(b)

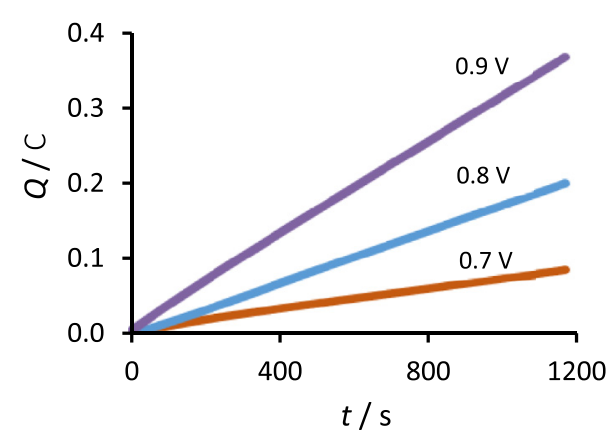

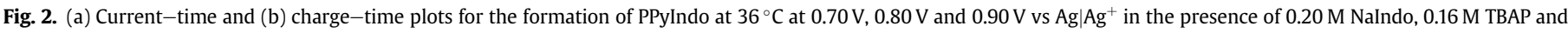
$0.20 \mathrm{M}$ pyrrole dissolved in ethanol. 
(a)

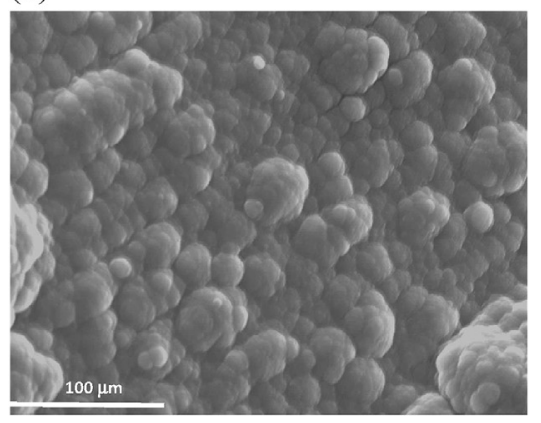

(c)

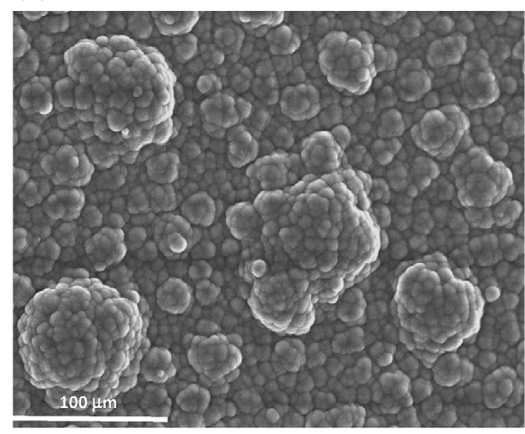

(b)

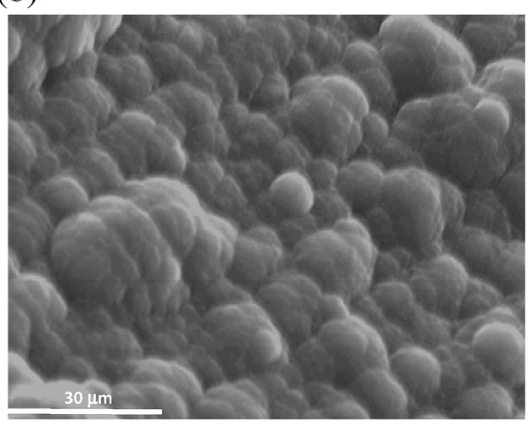

(d)

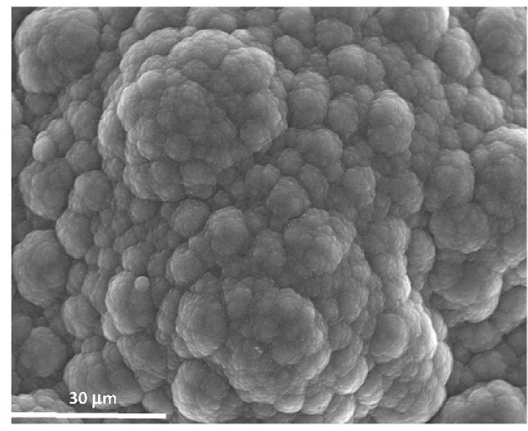

Fig. 4. SEM micrographs of PPyIndo (a) and (b) and PPySul (c) and (d) deposited at $0.90 \mathrm{~V} \mathrm{vs} \mathrm{Ag} \mid \mathrm{Ag}^{+}$to a charge of $2.8 \mathrm{C} \mathrm{cm}{ }^{-2}$.

globular structures appear to be somewhat larger for PPySul reaching diameters of about $100 \mu \mathrm{m}$, otherwise the morphologies are similar. It is also clear from these micrographs that there are no insoluble precipitates of the drug molecules on the surface. This is different to that reported by Ryan et al. [22], where crystal-like shards of diclofenac were seen dispersed throughout the polymer formed in an aqueous solution. Although the diclofenac salt was soluble in the aqueous electropolymerisation solution, the local acidification at the polymer solution interface shifted the equilibrium to favour the un-dissociated insoluble molecule. As the $\mathrm{pKa}$ values of indomethacin and sulindac, 3.96 and 4.26 in water at $25{ }^{\circ} \mathrm{C}$, are relatively high some un-dissociated drug molecules will be formed during electropolymerisation. However, these neutral molecules are more soluble in ethanol and are removed from the surface enabling doping of the polymer by the remaining anionic species.

\subsection{Electroactivity, exchange properties and doping levels}

The electroactivity and exchange properties of PPyIndo and PPySul were studied using cyclic voltammetry and EQCM in $0.1 \mathrm{M}$ $\mathrm{NaCl}$, as this chloride-containing solution was used as the release medium. The voltammograms recorded for PPySul and PPyIndo are compared with a $\mathrm{PPyCl}$ film that was formed in an aqueous $0.10 \mathrm{M}$ $\mathrm{NaCl}$ solution, Fig. 5 . The polymer films were deposited at $0.90 \mathrm{~V}$ vs $\mathrm{Ag} \mid \mathrm{Ag}^{+}$to a total charge of $0.35 \mathrm{C}\left(2.8 \mathrm{C} \mathrm{cm}^{-2}\right)$. The data presented show the 20th cycle, and at this point steady-state conditions are evident and the ion exchange involves the chloride and/or sodium ions from the electrolyte. It is clear from this figure that the PPySul and PPyIndo films are electroactive and they are reduced and oxidised as the potential is cycled between the upper and lower potential limits. The redox properties of $\mathrm{PPyCl}$ are consistent with the expulsion of chloride anions as the polymer is reduced and the incorporation of chloride anions as the film is oxidised. These relatively slow events give the characteristic broad oxidation and
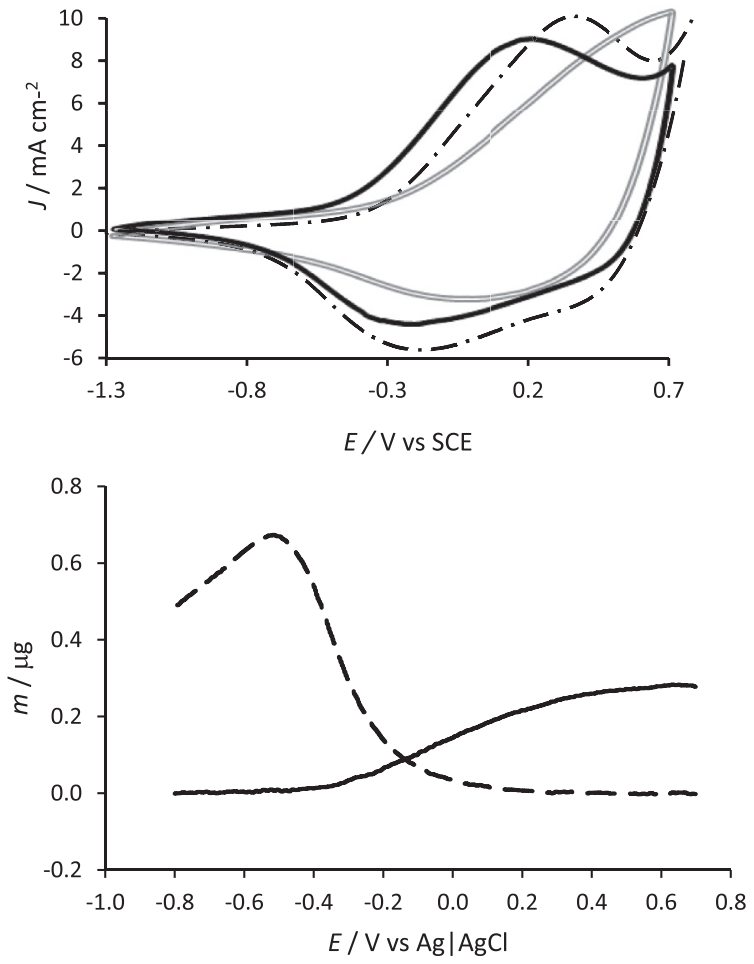

Fig. 5. (a) Steady-state cyclic voltammograms, 20th cycle, recorded at a scan rate of $25 \mathrm{mV} \mathrm{s}^{-1}$ in the presence of $0.10 \mathrm{M} \mathrm{NaCl}(\mathrm{pH} \mathrm{3.0)}$ for --- PPyIndo, — PPySul and -$\mathrm{PPyCl}$ (b) mass plotted as a function of applied potential for PPyIndo recorded at $5 \mathrm{mV} \mathrm{s}^{-1}$ in $0.10 \mathrm{M} \mathrm{NaCl}--$ first cycle and - third cycle.

reduction waves. The voltammogram recorded for PPySul is somewhat different. The incorporation of chloride anions from the solution is shifted to higher potentials, with the oxidation wave extending from $-0.30 \mathrm{~V}$ to $0.70 \mathrm{~V}$ vs SCE. The broad reduction wave 
is also centred at a slightly higher potential with the peak potential at approximately $0.10 \mathrm{~V}$ vs SCE. This suggests that the incorporation of chloride anions is more difficult for the PPySul films. Similar effects were seen with PPyIndo, but in this case the incorporation of chloride anions appears at a lower potential compared to PPySul. These variations between the $\mathrm{PPyCl}$ formed in an aqueous solution and the PPySul and PPyIndo formed in ethanol may be related to a different polymer morphology or a slightly lower conductivity with the oxidation waves being shifted to higher potentials.

As the sulindac and indomethacin are relatively large, the incorporation of $\mathrm{Na}^{+}$is also likely to occur on reduction of the polymer films to give mixed ion exchange behaviour. Indeed, this is clearly evident in Fig. 5(b) where the mass recorded using EQCM is shown as a function of the potential for PPyIndo. The uptake of $\mathrm{Na}^{+}$ and water molecules is evident during the first cycle, where an increase in mass is observed at about $0.10 \mathrm{~V}$ vs $\mathrm{Ag} \mid \mathrm{AgCl}$. The mass increases at a higher rate between $-0.20 \mathrm{~V}$ and $-0.45 \mathrm{~V}$ vs $\mathrm{Ag} \mid \mathrm{AgCl}$, indicating a higher uptake of water and $\mathrm{Na}^{+}$. The mass loss observed between about $-0.50 \mathrm{~V}$ and $-0.80 \mathrm{~V}$ vs $\mathrm{Ag} \mid \mathrm{AgCl}$ can be attributed to the expulsion of the indomethacin, indicating that mixed ion exchange occurs. The data presented for cycle 3 are dominated by chloride exchange. As the oxidised polymer is reduced the previously incorporated chloride anions are now released and this is evident from approximately $0.50 \mathrm{~V}$ to $-0.30 \mathrm{~V}$ vs $\mathrm{Ag} \mid \mathrm{AgCl}$. Again, there is a small mass loss (about $0.04 \mu \mathrm{g} \mathrm{V}^{-1}$ ) observed at the lower potentials and this appears to be connected to the release of the indomethacin dopant.

The doping levels were estimated using Eq. (2) where the mass-charge term was obtained from EQCM data. In these equations, $M$ is the total mass of the deposited polymer, $Q$ is the charge reached, $M_{m}$ is the mass of the monomer, $M_{d o p}$ is the mass of the dopant, $x$ is the doping level and $F$ is Faraday's constant. As perchlorates were added to the electropolymerisation solution, competitive doping will occur and Eq. (2) was modified to include both perchlorate and the drug molecules as dopants, Eq. (3). In Fig. 6(a), typical mass-charge plots are shown for the formation of PPyIndo and PPySul. In the case of PPyIndo, there is a short induction period observed before the mass begins to increase. This may be due to the slow diffusion of the anionic indomethacin. After this initial induction time has elapsed, the mass-charge plot becomes linear, with a slope of $7.5 \times 10^{-4} \mathrm{~g} \mathrm{C}^{-1}$, indicating homogenous film growth on the EQCM gold electrode. A lower mass-charge slope of $5.4 \times 10^{-4} \mathrm{~g} \mathrm{C}^{-1}$ was obtained with sulindac, indicating the incorporation of less sulindac as a dopant, Using the mass-charge slopes and allowing $x_{\text {Total }}$, Eq. (4), to vary, the sulindac and indomethacin doping levels were estimated as a

(a)

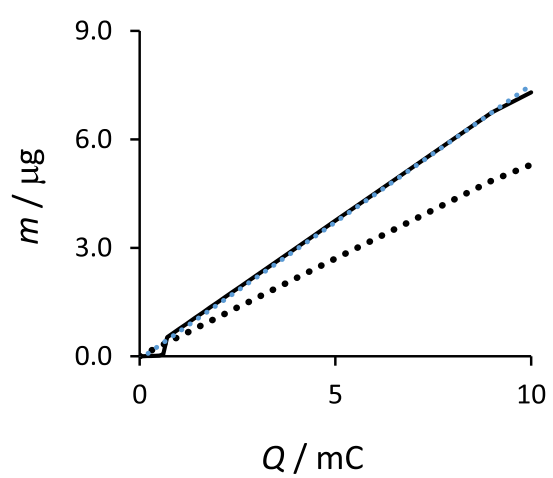

function of $x_{\text {Total }}$ and these estimated values are plotted in Fig. 6(b). It is evident from this analysis that the doping levels of sulindac are considerably lower, reaching values of approximately 0.10 , while much higher values of 0.28 are achieved with indomethacin.

$$
\frac{M}{Q}=\frac{M m+M d o p x}{(2+x) F}
$$

$\frac{M}{Q}=\frac{M_{p y}+M_{d r u g} x_{d r u g}+M_{C l O_{4}^{-}} x_{C l O_{4}^{-}}}{\left(2+x_{d r u g}+x_{C^{\prime} O_{4}^{-}}\right) F}$

$x_{\text {Total }}=x_{\text {drug }}+x_{\mathrm{ClO}_{4}^{-}}$

There is very little difference between the size of the molecules, Fig. 1, they both have a carboxyl group that is ionised and provides the site for doping within the polymer matrix. However, as can be seen in Fig. 1, the nitrogen in the indole ring of indomethacin is replaced in the sulindac by a double bond. Because of this double bond, the aryl substituent (aromatic ring) lies permanently in the cis configuration, whereas there is rotation around the single bond and more flexibility in the indomethacin molecule. This makes the indomethacin a potentially better dopant that can be more easily incorporated into the polymer. This is consistent with the higher indomethacin doping levels.

\subsection{The amount of perchlorate doped within the polymer matrix}

The amount of perchlorate doped within the polymer matrix was determined using a spectrophotometric method, employed by Ensafi and Rezaei [23]. This method was used as the absorbance of the perchlorate is not sufficiently sensitive for low concentrations. This involved adding an excess of a cationic dye, brilliant cresyl blue (BCB), which forms an insoluble ion pair with the perchlorate anion. The ion pair was then extracted into methyl isobutyl ketone and the absorbance of this solution was recorded. The PPySul and PPyIndo polymer films were polarised at $-0.70 \mathrm{~V}$ vs SCE for $60 \mathrm{~min}$ in a $0.10 \mathrm{M} \mathrm{NaCl}$ solution to release any perchlorate doped within the polymer film and then the solution was analysed for the perchlorate content as the ion pair. The amount of perchlorate released from PPyIndo and PPySul was $2.04 \times 10^{-8} \mathrm{~mol} \mathrm{~cm}^{-2}$ and $2.94 \times 10^{-8} \mathrm{~mol} \mathrm{~cm}^{-2}$, respectively. As the perchlorate is a relatively small dopant, with a low charge density, it should diffuse from the polymer within $60 \mathrm{~min}$, once the polymer is reduced. Indeed, no perchlorate was detected following a $15-30-$ min reduction period.

(b)

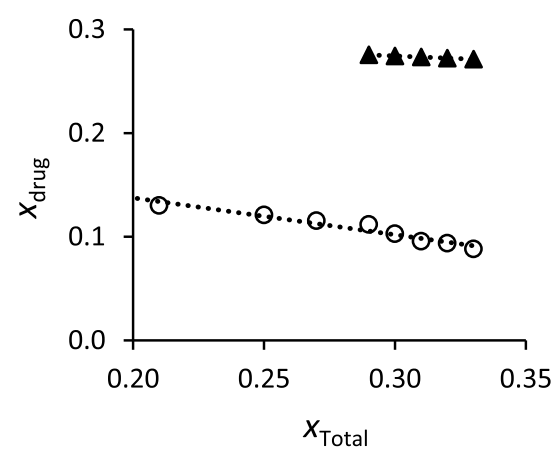

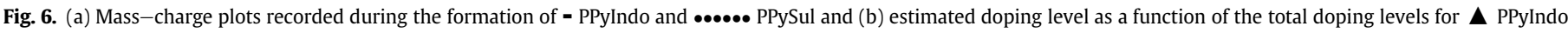
and $\bigcirc$ PPySul. 


\subsection{Release of Indo and Sul from the polymer matrix}

The release of indomethacin and sulindac from the polymer films was studied in an aqueous saline solution containing $0.10 \mathrm{M}$ $\mathrm{NaCl}$, at a pH of 6.0 at room temperature. While NaIndo and $\mathrm{NaSul}$ are soluble in ethanol, this medium is not suitable in terms of potential drug delivery applications. It is difficult to obtain accurate solubility data for the indomethacin and sulindac sodium salts in water, with values provided by chemical suppliers ranging from $0.50 \mathrm{~g} \mathrm{~L}^{-1}(1.4 \mathrm{mM})$ to $3.59 \mathrm{mg} \mathrm{L}^{-1}(9.8 \mu \mathrm{M})$. Therefore, the solubility was estimated using UV spectroscopy and by fitting the data to the Beer-Lambert law $(A=\varepsilon c d)$. The UV spectra of indomethacin and sulindac recorded in $0.10 \mathrm{M} \mathrm{NaCl}$ between $200 \mathrm{~nm}$ and $500 \mathrm{~nm}$ are shown in Fig. 7(a) where $\lambda_{\max }$ appears at $327 \mathrm{~nm}, 265 \mathrm{~nm}$ and $201 \mathrm{~nm}$ for sulindac and at $266 \mathrm{~nm}, 321 \mathrm{~nm}$ and $203 \mathrm{~nm}$ for indomethacin. The calibration curves shown in Fig. 7(b) and (c) were obtained for the absorption bands at the two higher $\lambda_{\max }$ values. Good linearity is seen up to about $100 \mu \mathrm{M}$ and then as shown in Fig. 7(b) for the sulindac system, the linearity is lost with higher concentrations and this is consistent with the precipitation of insoluble sulindac. The extinction coefficient, $\varepsilon$, was calculated as $3085 \mathrm{M}^{-1} \mathrm{~cm}^{-1}$ at $327 \mathrm{~nm}$ and $1135 \mathrm{M}^{-1} \mathrm{~cm}^{-1}$ at $265 \mathrm{~nm}$ for sulindac, while the corresponding values for indomethacin were $1301 \mathrm{M}^{-1} \mathrm{~cm}^{-1}$ at $266 \mathrm{~nm}$ and $865 \mathrm{M}^{-1} \mathrm{~cm}^{-1}$ at $321 \mathrm{~nm}$. These data clearly show that both indomethacin and sulindac are soluble at $\mu \mathrm{M}$ concentrations in $0.10 \mathrm{M} \mathrm{NaCl}$ and therefore the aqueous saline solution is a suitable medium for the release of the drugs from polypyrrole. To ensure that the concentrations of the drugs released from polypyrrole were within these linear calibration ranges the volume of the release medium was altered from $120 \mathrm{~mL}$ to $20 \mathrm{~mL}$, depending on the amount of the drug released.

As perchlorates are incorporated as dopants during the formation of PPyIndo and PPySul, these anions were firstly released at $-0.70 \mathrm{~V}$ vs SCE over a $60 \mathrm{~min}$ period in a $0.10 \mathrm{M} \mathrm{NaCl}$ solution. The reduced polymer was then polarised at $0.90 \mathrm{~V}$ vs $\mathrm{Ag} \mid \mathrm{Ag}^{+}$for $60 \mathrm{~min}$ in a solution of NaIndo or NaSul, but without the perchlorate salt. The TBAP salt was removed at this point as it is only required during the electropolymerisation step and this eliminates any incorporation of perchlorate within the polymer film. The release profiles for the PPyIndo and PPySul are shown for the 1st, 2nd and 3rd release periods in Fig. 8. During the first release experiment the perchlorate anion is ejected with the drug molecule, and during this initial release relatively high levels of the drug molecules are also expelled. Although the amount of indomethacin and sulindac released decreases with further release periods, approximately $0.80 \mu \mathrm{mol} \mathrm{cm}{ }^{-2}$ of Indo is released during the 2nd release period, giving a good rate of drug release. Similarly, approximately $0.38 \mu \mathrm{mol} \mathrm{cm} \mathrm{cm}^{-2}$ of Sul is released during the 2nd release event. This indicates that it is possible to eliminate the perchlorate by initially reducing the polymer to expel the perchlorate anions and then the drug molecules can be re-incorporated. The loss in the amount of the drugs released with repeated reduction and oxidation steps suggests that it is more difficult to re-oxidise the polymer to give the same levels of doping. This may be related to a loss in the conductivity of the polymer with repeated oxidation and reduction periods. It is also evident from these plots that significantly lower release rates are seen with the sulindac system. This is probably connected to the lower doping levels estimated for PPySul, Fig. 6 .

The influence of the applied potential on the release of the drugs is shown in Fig. 9(a). The polymers were deposited at $0.90 \mathrm{~V}$ vs $\mathrm{Ag} \mid \mathrm{Ag}^{+}$to a charge of $2.8 \mathrm{C} \mathrm{cm}^{-2}$ and the perchlorate anions were previously ejected and these data correspond to the second release period. It is clear from this figure that the applied potential has a significant influence on the drug release with a gradual increase in
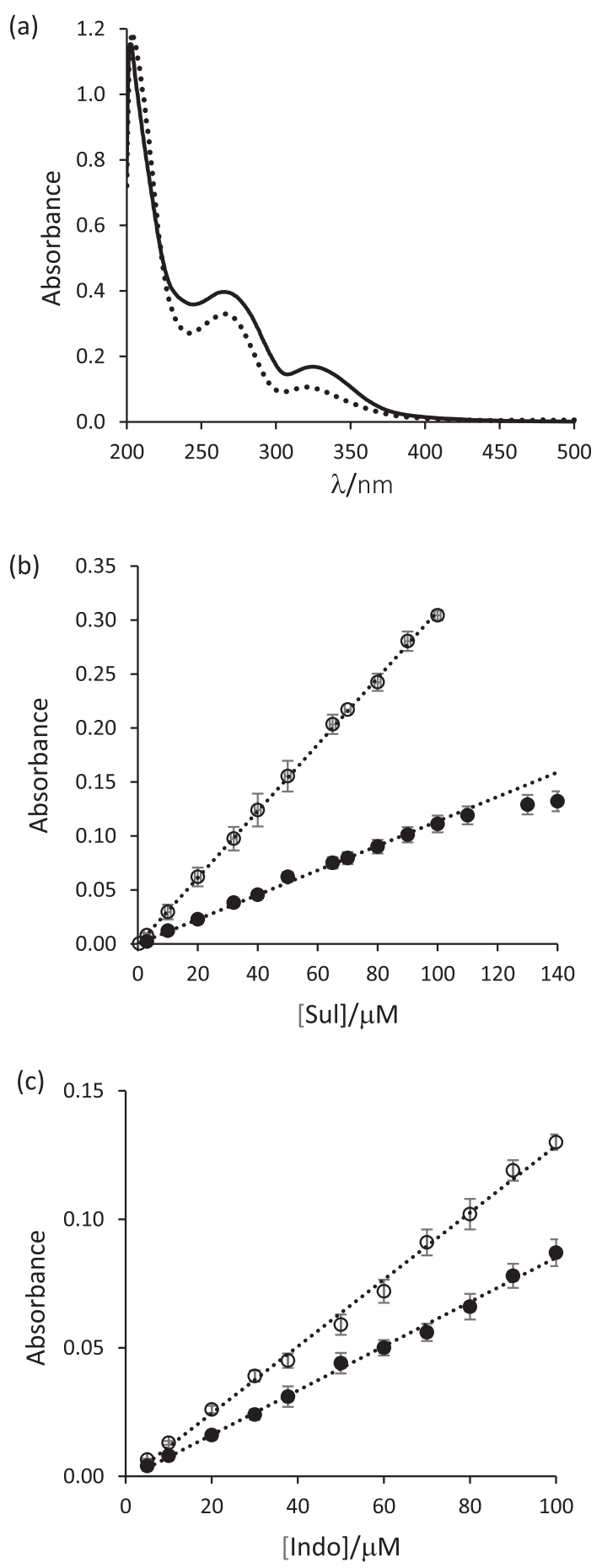

Fig. 7. (a) UV-Visible spectra recorded for $-6.0 \times 10^{-5} \mathrm{M}$ Sulindac and $\bullet \bullet \bullet \bullet \bullet$ $6.0 \times 10^{-5} \mathrm{M}$ Indomethacin dissolved in $0.10 \mathrm{M} \mathrm{NaCl}$, and calibration curves recorded in $0.10 \mathrm{M} \mathrm{NaCl}$ for (b) sulindac and (c) indomethacin $(n=3)$.

the amount of the drug released as the polymer becomes increasingly reduced. The release is more efficient between $-0.60 \mathrm{~V}$ and $-0.80 \mathrm{~V}$ vs SCE and this corresponds with the reduction of the polymer and is in good agreement with the EQCM data shown in Fig. 5(b). At more negative potentials, the release rate of the drug decreases as side reactions, mainly the hydrogen evolution reaction at the platinum substrate, prevail. This reaction consumes charge, limiting the reduction of the polymer and it also generates hydrogen and the liberation of these gaseous molecules may lead to 
(a)

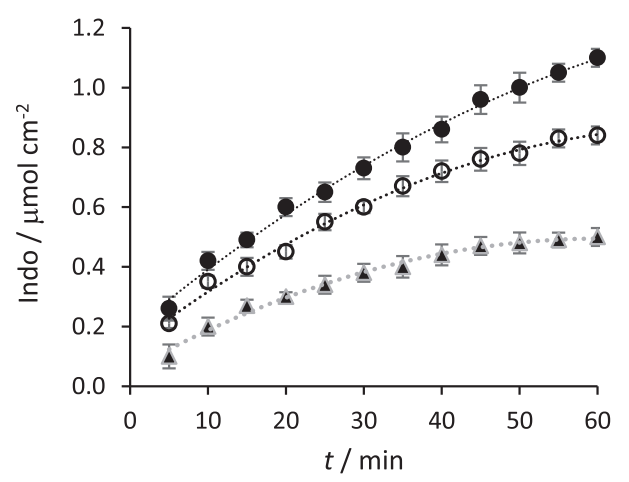

(b)

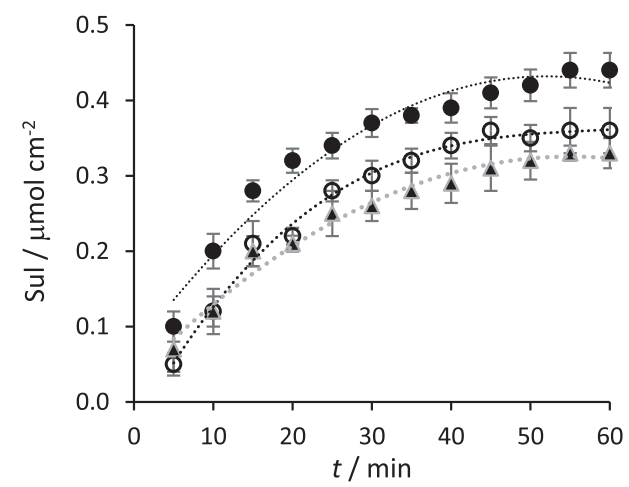

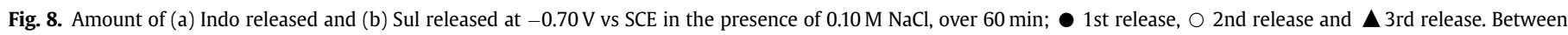
each release period the polymer was placed in NaIndo or NaSul for $60 \mathrm{~min}$ at a potential of $0.90 \mathrm{~V}$ vs $\mathrm{Ag}_{\mid} \mid \mathrm{Ag}^{+}(n=3)$.

(a)

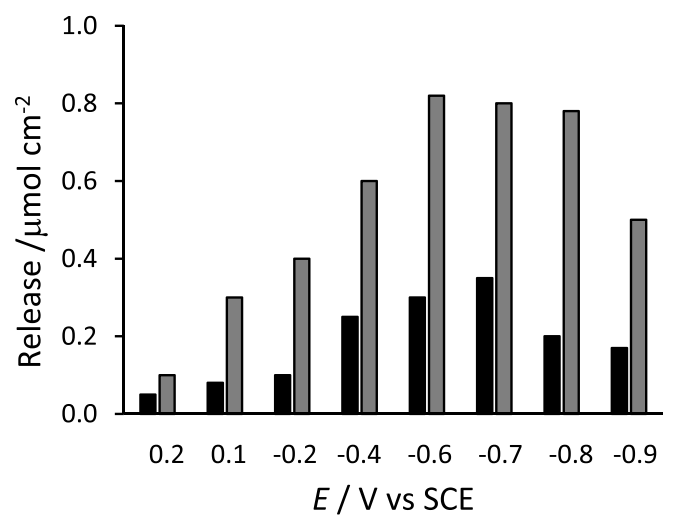

(b)

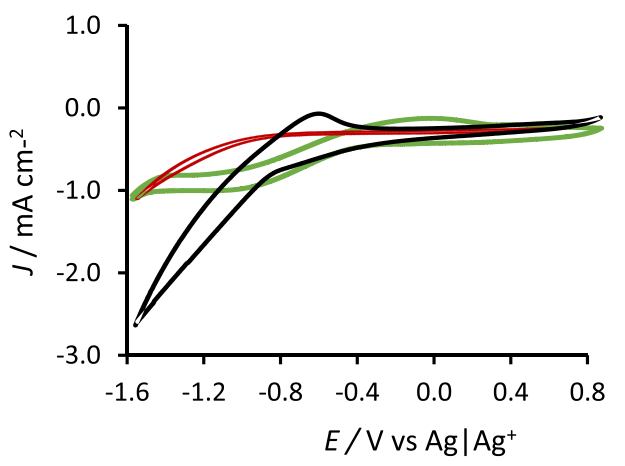

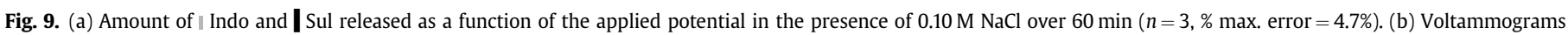
recorded on cycling platinum at $25 \mathrm{mV} \mathrm{s}^{-1}$ at $40^{\circ} \mathrm{C}$ in $-0.08 \mathrm{M}$ TBAP in ethanol and in the presence of $-0.20 \mathrm{M}$ Indo and $-0.12 \mathrm{M}$ Sul.

local delamination of the polymer from the substrate, further inhibiting the reduction of the polymer. In addition, as shown in Fig. 9(b), sulindac is susceptible to reduction, where the $>S=0$ group is reduced to a sulfide. The data shown in Fig. 9(b) were recorded in ethanol with $0.12 \mathrm{M}$ NaSul dissolved in 0.08 M TBAP and for comparative purposes the voltammetry of NaIndo is shown while the electrochemistry of platinum is also shown in the supporting TBAP electrolyte. The reduction of sulindac begins at about $-0.80 \mathrm{~V}$ vs $\mathrm{Ag} \mathrm{Ag}^{+}$and the current reaches $2 \mathrm{~mA} \mathrm{~cm}{ }^{-2}$ at $-1.2 \mathrm{~V}$ vs $\mathrm{Ag} \mid \mathrm{Ag}^{+}$. On the other hand, indomethacin shows no electrochemistry with low currents measured between $0.80 \mathrm{~V}$ and $-1.4 \mathrm{~V}$ vs $\mathrm{Ag} \mid \mathrm{Ag}^{+}$. Indeed, the presence of indomethacin in the solution inhibits the formation of the platinum oxides/hydroxides, probably by adsorbing at the platinum-solution interface. The sulindac released from PPySul is at a much lower concentration and its reduction in aqueous solutions will be shifted to a lower potential. This indicates that sulindac can be released without any conversion to the sulfide at potentials between $-0.40 \mathrm{~V}$ and $-0.70 \mathrm{~V}$ vs SCE.

In order to estimate how much of the drug was available for release, release studies were carried out over a $15 \mathrm{~h}$ period and the concentration of the drug released was used to give an approximate value for the amount of the drug available for release. Using this approach, it was estimated that $85 \%$ of sulindac and $76 \%$ of indomethacin is released after $1 \mathrm{~h}$. These data compare well with a number of studies with other release systems. For example, Zeleňák et al. [24], used ordered cubic nanoporous silica supports for delivery of indomethacin and found that the percentage of indomethacin released by diffusion over a $72 \mathrm{~h}$ period varied between $83 \%$ and $57 \%$ depending on the surface modification. These relatively high quantities of drug release from the polymer may be connected to the high charge consumed during the formation of the polymers. The thickness of the polymer films was estimated as $5.8 \mu \mathrm{m}$ using Faraday's Law, Eq. (5), where $M$ is the molar mass of pyrrole, $q$ is the charge, $A$ is the surface area of the electrode, $z$ is the number of electrons transferred, $F$ is Faraday's constant and $\rho$ is the density of polypyrrole, taken as $1.5 \mathrm{~g} \mathrm{~cm}^{-3}$.

$x=\frac{q M}{\rho A z F}$

It is evident from Fig. 5(b) that in addition to the release of the drug molecules that $\mathrm{Na}^{+}$ingress, accompanied by solvated water molecules, occurs on reduction of the polymer film, as illustrated in Eqs. (6) and (7). This mixed ion exchange will reduce the amount of the drug available for release. As the insertion of $\mathrm{Na}^{+}$begins at about $-0.20 \mathrm{~V}$ vs $\mathrm{Ag} \mid \mathrm{AgCl}$, the release of the drug molecules without the incorporation of $\mathrm{Na}^{+}$is difficult to achieve. As shown in Fig. 9(a) it is possible to release the drug molecules at 0.10 and $0.20 \mathrm{~V}$ vs SCE, however the release rate is reduced considerably, 
compared to potentials in the vicinity of $-0.60 \mathrm{~V}$ to $-0.80 \mathrm{~V}$ vs SCE.

$$
\begin{aligned}
& \operatorname{PPy}^{\mathrm{n}+} n \mathrm{Sul}^{-}+\mathrm{ze}^{-}+(n-m) \mathrm{Na}^{+} \\
& \quad+b \mathrm{H}_{2} \mathrm{O} \rightarrow \operatorname{PPy}^{\circ}(n-m) \mathrm{Sul}^{-}(n-m) \mathrm{Na}^{+} b \mathrm{H}_{2} \mathrm{O}+m \mathrm{Sul}^{-}
\end{aligned}
$$

$$
\begin{aligned}
& \text { PPy }^{\mathrm{n}+} n \text { Indo }^{-}+\mathrm{ze}^{-} \\
& +(n-m) \mathrm{Na}^{+} b \mathrm{H}_{2} \mathrm{O} \rightarrow \mathrm{PPy}^{\circ}(n-m) \mathrm{Indo}^{-}(n-m) \mathrm{Na}^{+} b \mathrm{H}_{2} \mathrm{O} \\
& + \text { Indo }^{-}
\end{aligned}
$$

Using the EQCM data and assuming that the doping levels estimated during the early stages of film formation are maintained during the formation of the bulk polypyrrole films, the amount of indomethacin and sulindac incorporated as dopants was estimated. Using the doping levels of 0.28 for indomethacin and 0.10 for sulindac, and the mass-charge ratios of $7.5 \times 10^{-6} \mathrm{~g} \mathrm{C}^{-1}$ and $5.4 \times 10^{-6} \mathrm{~g} \mathrm{C}^{-1}$ for indomethacin and sulindac, respectively, approximately $0.42 \mu \mathrm{mol}$ of indomethacin and $0.16 \mu \mathrm{mol}$ of sulindac are incorporated as dopants. This gives maximum release amounts of $3.3 \mu \mathrm{mol} \mathrm{cm}{ }^{-2}$ for indomethacin and $1.24 \mu \mathrm{mol} \mathrm{cm}{ }^{-2}$ for sulindac and this corresponds with approximately $30-40 \%$ of the drugs being released. This highlights a limitation of using polypyrrole in the development of a drug delivery system. Although it is unlikely that all of the dopants would be expelled on reduction of the polymer film, the mixed ion exchange behaviour will result in lower release rates, as a high fraction of the drug is maintained within the polymer matrix. This is clearly evident with these medium-sized drugs with molecular weights of $356 \mathrm{~g} \mathrm{~mol}^{-1}$. Furthermore, the conformation of the molecule and its lack of rotation has a role to play in how the drug molecule is incorporated within the polymer matrix as illustrated from a comparison of the sulindac and indomethacin systems.

\section{Conclusions}

The poorly water soluble drugs, indomethacin and sulindac, were incorporated as dopants into polypyrrole from an ethanol-containing solution. Although higher temperatures were required to generate the polymer films and a non-aqueous electropolymerisation solution was used, the polymers exhibit good redox properties. It was not possible to form the polymers without a supporting electrolyte that contained perchlorate anions and this gave rise to competitive doping. However, the perchlorate anions are relatively small and these were released initially on reduction of the polymer film. The drug molecules were then re-doped within the polymer matrix in the absence of the perchlorate anions. The drug molecules were subsequently released on reduction of the polymer films. As the drug molecules are relatively large, mixed-ion exchange behaviour was observed and this is clearly a limitation in the development of polypyrrole or polypyrrole composite materials as a drug delivery system. In order to avoid the ingress of $\mathrm{Na}^{+}$from the release medium, the drug must be released at a potential higher than $-0.05 \mathrm{~V}$ vs $\mathrm{Ag} \mid \mathrm{AgCl}$, Fig. 5, which corresponds to a release potential of $-0.10 \mathrm{~V}$ vs SCE in Fig. 9.

\section{Acknowledgements}

The authors would like to acknowledge funding from the Irish Research Council for Science, Engineering and Technology (IRCSET) Ireland.

\section{References}

[1] R. Jain, N. Jadon, A. Pawaiya, Polypyrrole based next generation electrochemical sensors and biosensors: a review, Trends Anal. Chem. 97 (2017) $363-373$.

[2] B. Zinger, L.L. Miller, Time release of chemicals from polypyrrole films, J. Am. Chem. Soc. 106 (1984) 6861-6863.

[3] E.M. Ryan, C.B. Breslin, Formation of polypyrrole with dexamethasone as a dopant: its cation and anion exchange properties, J. Electroanal. Chem. 824 (2018) 188-194.

[4] L.L. Miller, X.O. Zhou, Poly (N-methylpyrrolylium) poly (styrenesulfonate)-a conductive, electrically switchable cation exchanger that cathodically binds and anodically releases dopamine, Macromolecules 20 (1987) 1594-1597.

[5] M. Hepel, F. Mahdavi, Application of the electrochemical quartz crystal microbalance for electrochemically controlled binding and release of chlorpromazine from conductive polymer matrix, Microchem. J. 56 (1997) 54-64.

[6] D. Svirskis, M. Sharma, Y. Yu, S. Garg, Electrically switchable polypyrrole film for the tunable release of progesterone, Ther. Deliv. 4 (2013) 307-313.

[7] B. Massoumi, A. Entezami, Electrochemically-controlled binding and release of dexamethasone from conducting polymer bilayer films, J. Bioact. Compat Polym. 17 (2002) 51-62.

[8] J.-M. Pernaut, J.R. Reynolds, Use of conducting electroactive polymers for drug delivery and sensing of bioactive molecules. A redox chemistry approach, J. Phys. Chem. B 104 (2000) 4080-4090.

[9] R.T. Richardson, A.K. Wise, B.C. Thompson, B.O Flynn, PJ Atkinson, N.J. Fretwell, J.B. Fallon, G.G. Wallace, R.K. Shepherd, G.M. Clark, Polypyrrole-coated electrodes for the delivery of charge and neurotrophins to cochlear neurons, Biomaterials 30 (2009) 2614-2624.

[10] S. Sirivisoot, R.A. Pareta, T.J. Webster, Conductive nanostructured polymer electrodeposited on titanium as a controllable, local drug delivery platform, J. Biomed. Mat. Research, Part A 99 (2011) 586-597.

[11] R. Wadhwa, C.F. Lagenaue, X.T. Cui, Electrochemically-controlled release of dexamethasone from conducting polymer polypyrrole coated electrode, J. Contr. Release 110 (3) (2006) 531-541.

[12] B.C. Thompson, S.E. Moulton, J. Ding, R. Richardson, A. Cameron, S. O'Leary, G.G. Wallace, G.M. Clark, Optimising the incorporation and release of a neurotrophic factor using conducting polypyrrole, J. Contr. Release 116 (2006) $285-294$.

[13] K. Almira, T. Asta, R.A. Stasys, Biocompatibility of polypyrrole particles: an invivo study in mice, J. Pharm. Pharmacol. 59 (2) (2007) 311-315.

[14] P.M. George, A.W. Lyckman, D.A. LaVan, A. Hegde, Y. Leung, R. Avasare, C. Tesa, P.M. Alexander, R. Langer, M. Sur, Fabrication and biocompatibility of polypyrrole implants suitable for neural prosthetics, Biomaterials 26 (2005) 3511-3519.

[15] X. Luo, X.T. Cui, Sponge-like nanostructured conducting polymers for electrically controlled drug release, Electrochem. Commun. 11 (2009) 1956-1959.

[16] D. Uppalapati, M. Sharma, Z. Aqrawe, F. Coutinho, I.D. Rupenthal, B.J. Boyd Jadranka Travas-Sejdic, D. Svirskis, Micelle directed chemical polymerization of polypyrrole particles for the electrically triggered release of dexamethasone base and dexamethasone phosphate, Int. J. Pharmaceut. 543 (2018) $38-45$.

[17] S. Jiang, Y. Sun, X. Cui, X. Huang, Y. He, S. Ji, W. Shi D. Ge, Enhanced drug loading capacity of polypyrrole nanowire network for controlled drug release, Synth. Met. 163 (2013) 19-23.

[18] M. Zhou, J. Heinze, Electropolymerisation of pyrrole and electrochemical study of polypyrrole. 3. Nature of water effect in acetonitrile, J. Phys. Chem. B 103 (1999) 8451-8457.

[19] F. Beck, M. Oberst, R. Jansen, On the mechanism of the film-forming electropolymerization of pyrrole in acetonitrile with water, Electrochim. Acta 35 (1990) 1841-1848.

[20] V.M. Ovando-Medina, R.D. Peralta, E. Mendizabal, J. Martinez-Gutierrez, T.E. Lara-Ceniceros, R. Ledezma-Rodriguez, Synthesis of polypyrrole nanoparticles by oil-water microemulsion polymerization with narrow size distribution, Colloid Polym. Sci. 289 (7) (2011) 759-765.

[21] J.M. Ko, H.W. Rhee, S.-M. Park, C.Y. Kim, Morphology and electrochemical properties of polypyrrole films prepared in aqueous and nonaqueous solvents, J. Electrochem. Soc. 137 (1990) 905-909.

[22] E.M. Ryan, C.B. Breslin, S.E. Moulton, G.G. Wallace, The effect of dopant $\mathrm{p} K_{\mathrm{a}}$ and the solubility of corresponding acid on the electropolymerisation of pyrrole, Electrochim. Acta 92 (2013) 276-284.

[23] A.A. Ensafi, B. Rezaei, Automatic liquid-liquid extraction flow injection analysis determination of trace amounts of perchlorate with spectrophotometric detection, Anal. Lett. 31 (1998) 167-177.

[24] V. Zeleňák, D. Halamová, M. Almáši, L. Žid, A. Zeleňáková, O. Kapusta, Ordered cubic nanoporous silica support MCM-48 for delivery of poorly soluble drug indomethacin, Appl. Surf. Sci. 443 (2018) 525-534. 